\title{
MRI spectroscopic and tractography studies indicate consequences of long-term ketogenic diet
}

\author{
Kinga Gzieło ${ }^{1} \cdot \mathrm{Krzysztof} \mathrm{Janeczko}^{1} \cdot$ Władysław Węglarz $^{3} \cdot \mathrm{Krzysztof} \mathrm{Jasiński}^{3} \cdot \mathrm{Krzysztof} \mathrm{Kłodowski}^{2}$. \\ Zuzanna Setkowicz ${ }^{1}$ (1)
}

Received: 20 January 2020 / Accepted: 2 July 2020 / Published online: 17 July 2020

(c) The Author(s) 2020

\begin{abstract}
To maintain its functional abilities, the mature brain obtains energy from glucose produced in carbohydrate metabolism. When carbohydrates are eliminated from the diet, the energy comes from the oxidation of fatty acids. In this metabolic state called ketosis, ketone bodies are formed: $\beta$-hydroxybutyric acid ( $\mathrm{bHb}$ ), acetone, and acetoacetate as alternative source of energy passing through the blood-brain barrier easily. The ketosis state can be achieved through various strategies like caloric restriction, supplementation with medium-chain triglycerides, intense physical training, or ketogenic diet (KD). Using KD, drug-resistant epilepsy has been successfully treated in children and adults. It can also exert neuroprotective influences in cases of brain damage, glioblastoma multiforme, and Alzheimer's or Parkinson's diseases. Although many possible mechanisms of KD activity have been proposed, newer hypotheses appear with the research progress, mostly characterizing the brain under pathological but not normal conditions. Since different pathological conditions may affect the mechanism of $\mathrm{KD}$ action differently, additional research on the normal brain appears reasonable. For this purpose, young adult rats were treated with 4-month-lasting KD. Then, MRI structural measurements, spectroscopy, and tractography were performed. The procedures revealed significant increases in the concentration of glutamine, glutamate, glutathione and NAA, accompanied by changes in the pattern of neuronal connections of the striatum and hippocampal formation. This implies a possible involvement of these structures in the functional changes occurring in the brain after KD application. Thus, the investigations on the normal brain add important details concerning mechanisms underlying KD effects without their possible modification by a pathological status.
\end{abstract}

Keywords Ketogenic diet $\cdot$ MRI spectroscopy $\cdot$ Normal rat $\cdot$ Tractography

\begin{tabular}{lll} 
Abbreviations & Asp & Aspartate \\
Acn Acetone & ATP & Adenosine triphosphate \\
Act Acetate & bHb & $\beta$-Hydroxybutyric acid \\
Ala L-Alanine & CPK & Creatine phosphokinase \\
ALP Alkaline phosphatase & Cr & Creatine \\
& FA & Fractional anisotropy \\
& GABA & $\gamma$-Aminobutyric acid \\
K. Gzieło and K. Janeczko contributed equally to this work. & GAD & Glutamic acid decarboxylase \\
\hline $\begin{array}{l}\text { Zuzanna Setkowicz } \\
\text { zuzanna.setkowicz-janeczko@uj.edu.pl }\end{array}$ & GCL & Glutamate cysteine ligase \\
Department of Neuroanatomy, Faculty of Biology, & Glc & Glucose \\
Gronostajowa 9, 30-387 Kraków, Poland & Gln & Glutamine \\
$\begin{array}{l}\text { Faculty of Physics and Applied Computer Science, AGH } \\
\text { University of Science and Technology, 30-059 Kraków, }\end{array}$ & Glu & Glutamate \\
Poland & GPC & Glycerophosphocholine \\
Department of Magnetic Resonance Imaging, Institute & GSH & Glutathione \\
of Nuclear Physics Polish Academy of Sciences, & HCT & Hematocrit \\
Radzikowskiego 152 St, 31-342 Kraków, Poland & HGB & Hemoglobin
\end{tabular}




$\begin{array}{ll}\text { LDH } & \text { Lactate dehydrogenase } \\ \text { MCH } & \text { Mean corpuscular hemoglobin } \\ \text { MCHC } & \text { Mean corpuscular hemoglobin concentration } \\ \text { MCV } & \text { Mean corpuscular volume } \\ \text { NAA } & N \text {-Acetylaspartate } \\ \text { NAAG } & N \text {-Acetylaspartylglutamate } \\ \text { PCh } & \text { Phosphocholine } \\ \text { Pcr } & \text { Phosphocreatine } \\ \text { PLT } & \text { Blood platelets } \\ \text { RBC } & \text { Red blood cells } \\ \text { ROS } & \text { Reactive oxygen species } \\ \text { Tau } & \text { Taurine } \\ \text { TCA } & \text { Citric acid cycle } \\ \text { TG } & \text { Trigliceryde } \\ \text { UA } & \text { Uric acid } \\ \text { WBC } & \text { White blood cells }\end{array}$

\section{Introduction}

Under normal circumstances, energy required for proper brain functioning in adults derives from glucose generated in carbohydrate metabolism (Vannucci and Vannucci 2000). When carbohydrates are eliminated from the diet, energy can be obtained from fatty acid oxidation. This process generates the amount of acetyl-co molecules sufficient for the synthesis of acetylacetic acid in the liver. It can be either spontaneously transformed into acetone or enzymatically transformed into beta-hydroxybutyric acid (ketone bodies, $\mathrm{bHb}$ ). This reaction can run in both directions in the presence of beta-hydroxybutyric acid dehydrogenase (Bailey et al. 2005). Ketone bodies generated in this way are an alternative energy source for metabolism. The status in which the synthesis of ketone bodies is accelerated is called ketosis. Ketone bodies are transported to the circulation and then to extrahepatic tissues where they are used as ATP precursors. They can also reach the brain easily crossing the blood-brain barrier; acetone via simple diffusion, beta-hydroxybutyric acid and acetylacetic acid through transporters, the expression of which is connected with ketosis level (Bailey et al. 2005). Upon crossing the blood brain barrier, ketones are transported across cell plasma membranes via monocarboxylate transporters 1 and 2 in astrocytes and neurons, respectively (Vijay and Morris 2014).

Guzman and Blazquez (2001) presumed that ketone bodies might have a potential to arise also in astrocytes and then be transported into neurons. This astrocyte-neuron transportation hypothesis seems to be very interesting and worth studying in detail.

A diet with significantly reduced protein and carbohydrate is commonly called ketogenic (KD) and has been described by many authors as having protective effects. To date, several mechanisms of the ketogenic diet have been proposed, despite the fact that along with the increase of knowledge on this subject, the number of hypotheses has also been growing. It was also demonstrated that as short as a 3-week feeding of rats with KD gave rise to elevation of glutathione, a free radical scavenger. It was most probably associated with a simultaneous increase of glutamate cysteine ligase (GCL), an enzyme that limits the GSH synthesis rate (Jarrett et al. 2008).

Ketones may also affect the activity of sirtuin 3, which is the major mitochondrial deacetylase (Rardin et al. 2013). Due to its enhanced activity, the ROS production diminishes, thereby preventing from oxidative stress episodes. The ketogenic diet suppressed dissociation of a proapoptotic factor Bad from the chaperon protein 14-3-3 which was demonstrated to occur in the kainate model of seizures (Noh et al. 2005). Other studies showed that the ketogenic diet increased the level of the inhibitory neurotransmitter GABA and raised the expression of glutamic acid decarboxylase (GAD), an enzyme participating in GABA synthesis (Cheng et al. 2004; Dahlin et al. 2005; Yudkoff et al. 2005; Gama et al. 2015; Melo et al. 2006).

The neuroprotective potential of ketogenic diet related to epileptic seizures can be effective not only by changing levels of neurotransmitters, but also by independent modification of the neuronal membrane potential. After entering the TCA cycle, ketone bodies can increase ATP levels by affecting the ATP-dependent potassium channel and leading, therefore, to increased polarization of the neuronal membrane (Koppel and Swerdlow, 2017).

Recently, KD is frequently applied for the treatment of neurodegenerative diseases such as epilepsy, migraine, brain damage and Alzheimer's or Parkinson's diseases (AD, PD), autism, sleep disorders, amyotrophic lateral sclerosis (ALS), multiple sclerosis (MS), pain, depression and even cancer (Stafstrom and Rho 2012) or to lose body weight. The reasons leading to the use of different dietary treatments as attempts to cure the diseases or alleviate their symptoms are both a lack of effective pharmacological treatment, and/ or great needs for more natural methods without commonly occurring adverse side effects. Furthermore, it is believed that normally functioning neurometabolic paths can be modified by an appropriately selected diet (Stafstrom and Rho 2012).

However, the ameliorating KD effects were documented using mostly animal models or clinical trials on individuals whose metabolism was modified, or even disturbed by different damages or ongoing disease processes. Unlike those studies, our previous research on normal animals (Gzieło et al. 2019), which were not subjected to any previous experimental procedure, showed that KD led to morphological transformation of glial cells and quantitative increases of calretinin-containing interneurons. Using the same experimental design, our research is, therefore, aimed at effects of 
long-term, 4-month-lasting KD on brain anatomy (structural MRI scans), subtle changes in the brain metabolism (MRI spectroscopy), and intracerebral connections (MRI-based tractography). To our best knowledge, such studies have not been conducted so far. Only brain glucose and ketone uptake were tested in 4- or 21-month-old animals after 14-day-lasting KD (Roya et al. 2012). These studies showed only that the region-to-whole brain ratio of cerebral metabolic rate of glucose was $37-41 \%$ lower in the cortex and $40-45 \%$ lower in the cerebellum compared to cerebral metabolic rate of cerebral metabolic rate of acetoacetate in 4 month- and 21 month-old rats (Roya et al. 2012). In the study by Zhang et al. (2018a, b), NAA, Cho, CR contents were assessed with MRI spectroscopy in animals fed a ketogenic diet after TBI. In addition, studies by Huang et al. (2019) showed that $\mathrm{KD}$ applied for 3 months in mice did not cause changes in behavior when tested. But when the threshold for pentylenetetrazole-induced seizures was tested, it turned out to be higher in animals on KD.

\section{Materials and methods}

\section{Animal treatment}

In the experiment, we used twenty male Wistar rats from the Animal Clinic of the Pharmaceutical Department of the Jagiellonian University Medical College, Krakow. All procedures were carried out in accordance with the permission no. 122/2015 of the First Local Ethical Committee on Animal Testing at the Jagiellonian University in Krakow. At the age of 60 days, the rats were randomly divided into two equal groups and then subjected to MRI spectroscopy as described below. At the age of 65 days, in one of the animal groups, a ketogenic diet (ssniff ${ }^{\circledR}$ EF R/M with $80 \%$ Fat, www.ssnif f.com) was introduced, while the second group received a standard diet (Labofeed H Standard ND, Morawski). The animals on each type of diet were kept in individual cages for 4 months. The food consumed was weighed daily and the animals were weighed once a week. The composition of the feed in groups on each type is presented in Table 1.

Blood levels of glucose and ketone bodies were measured at the beginning of the diet administration and repeated every two weeks using a Optium Xido glucometer (Abbott Diabetes Care Ltd. Oxon, UK). After 4 months of treatments

Table 1 Percentage composition of diets used in the experiment

\begin{tabular}{lcl}
\hline Nutrient & Ketogenic diet & Standard diet \\
\hline Lipids & 93 & 10 \\
Carbohydrates & 0 & 60 \\
Proteins & 6 & 30 \\
\hline
\end{tabular}

with these diets, MRI imaging, the same as that at the beginning of the experiment (spectroscopy), was repeated. Thereafter, the animals were anesthetized and venous blood was collected for peripheral blood count and biochemistry. Then perfusion-fixation was done with $3.7 \%$ formaldehyde in phosphate buffer, pH 7.4 (Setkowicz and Ciarach 2007; Gzielo et al. 2017). Brains and paratesticular fat were weighed. Finally, the brains were subjected to ex vivo MRI structural measurements and DTI (Diffusion Tensor Imaging).

\section{MRI spectroscopy before diet administration}

The baseline concentrations of metabolites (Ala, Asp, Cr, PCr, GABA, Glc, Gln, Glu, GPC, PCh, GSH, Ins, Lac, $\mathrm{NAA}, \mathrm{NAA}+\mathrm{NAAG}, \mathrm{Cr}+\mathrm{PCr}$, Glu + Gln, AcAc, Acn and $\mathrm{bHb})$ scaled to the water signal were measured in single volume voxels in the cerebral cortex $(1.8 \times 4 \times 4 \mathrm{~mm}$ size, Fig. 1a) and the hippocampal formation $(2 \times 8 \times 2 \mathrm{~mm}$ size, Fig. 1b). Only metabolites with good LCmodel fit reliability (Cramer-Rao lower bound (CRLB) less than 20\%) were included in further testing (Table 2).

\section{MRI spectroscopy after 4 months lasting diets}

In animals that were on ND or KD, levels of Ala, Asp, Cr, Pcr, GABA, Glc, Gln, Glu, GPC, PCh, GSH, Ins, Lac, NAA, $\mathrm{NAA}+\mathrm{NAAG}, \mathrm{Cr}+\mathrm{PCr}$, Glu + Gln, AcAc, Acn and bHb were evaluated in the same brain areas in the cerebral cortex and hippocampal formation, similarly as at the initial stage of the experiment. The final levels of particular metabolites were compared with those recorded before the diet implementation, and between the ND and KD groups. Differences were tested for statistical significance by means $t$ Student's test for normal data distribution, $p<0.05$ was considered statistically significant.

Magnetic resonance imaging and spectroscopy experiments were performed on a 9.4 $\mathrm{T}$ animal scanner (Biospec 94/20, Bruker, Ettlingen, Germany) running ParaVision 5.1. For in vivo measurements, BGA12S (Bruker) gradient system was used together with a quadrature transmit volume coil-T12054V3 (Bruker) and receive only rat brain surface coil-T11207V3 (Bruker).

Animals were placed in a water-heated rat bed with stereotactic fixation (Bruker) and nose cone to supply anesthesia. During the MRI, animal temperature, respiratory rate, and ECG were monitored with Small Animal Monitoring and Gating System, Model 1025 (SA Instruments, Inc. New York, USA). The animal temperature was kept between 37 and $38{ }^{\circ} \mathrm{C}$ and isoflurane (Aerrane, Baxter, Poland) concentration was $1.5 \%$ in a $1 / 2$ oxygen/air mixture.

Based on reference multislice RARE scans (axial, sagittal and coronal), localized spectroscopy voxel was located 

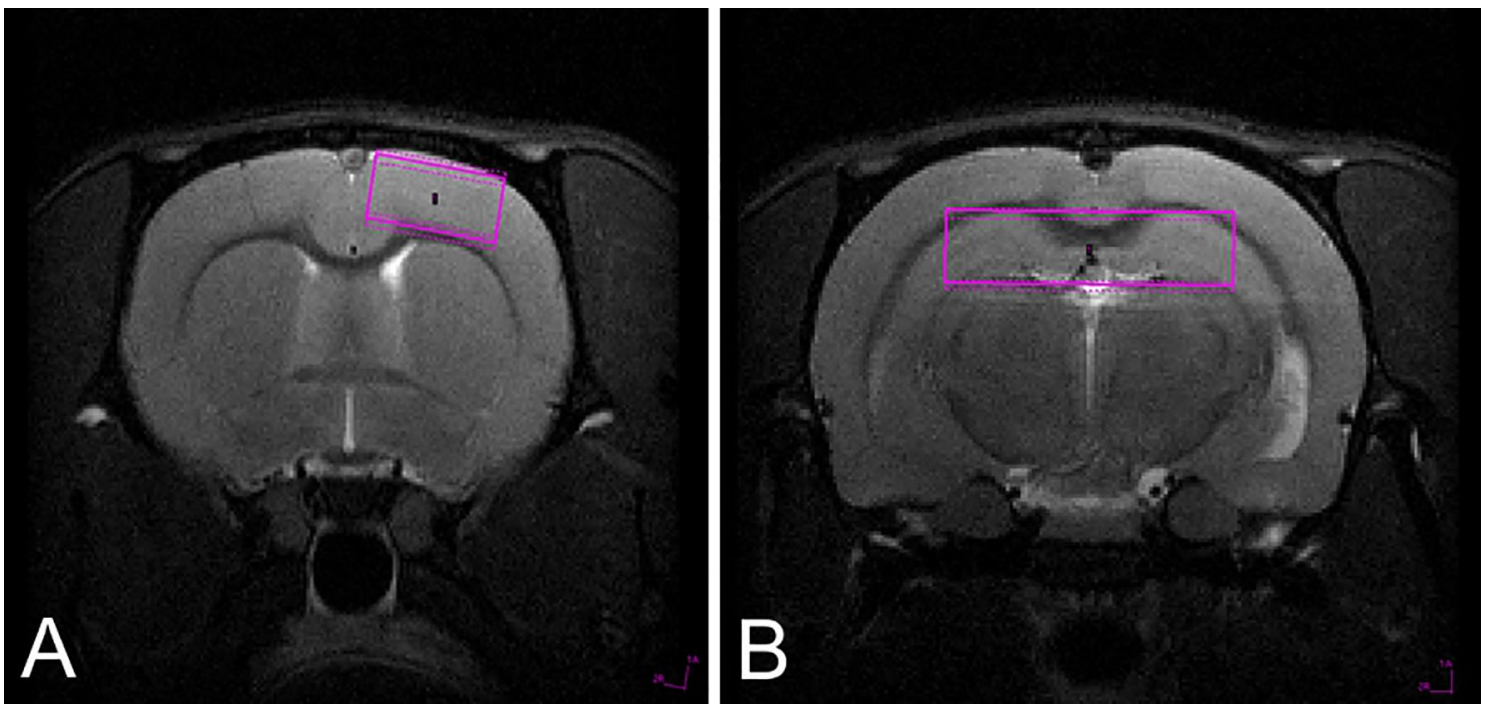

Fig. 1 Position of spectroscopy voxel for signal acquisition from the cerebral cortex (a) and hippocampal formation (b)

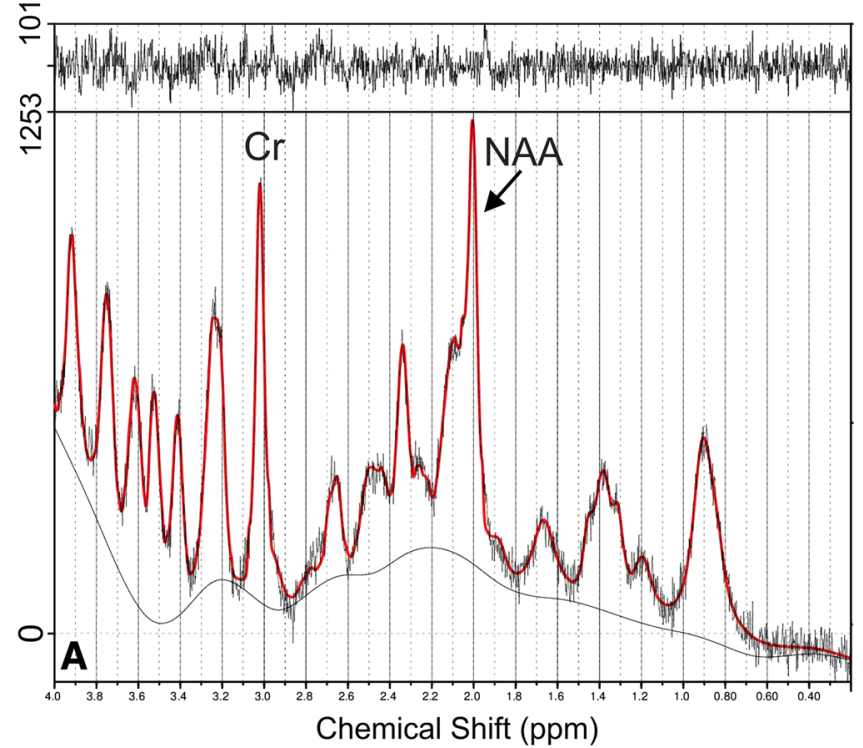

Fig. 2 Spectra from the cerebral cortex in the same animal before (a) and after (b) ketogenic diet application with examples of relative concentrations shown for creatine $(\mathrm{Cr})$ and $N$-acetylaspartate (NAA). The

in the hippocampal formation (Fig. 1b) and cerebral cortex (Fig. 1a). 1H MRS experiments were acquired using stimulated echo acquisition mode (STEAM). The acquisition parameters were as follows: echo time (TE) $3 \mathrm{~ms}$, repetition time (TR) 2500, mixing time $10 \mathrm{~ms}$, number of averages (NA) 700. The acquisition was triggered by animal respiration signal usually every second breath. VAPOR technique was used for water suppression and outer volume suppression (OVS) was applied as well. In case of hippocampal data acquisition, voxel size was $2 \times 8 \times 2 \mathrm{~mm}$ while for cerebral

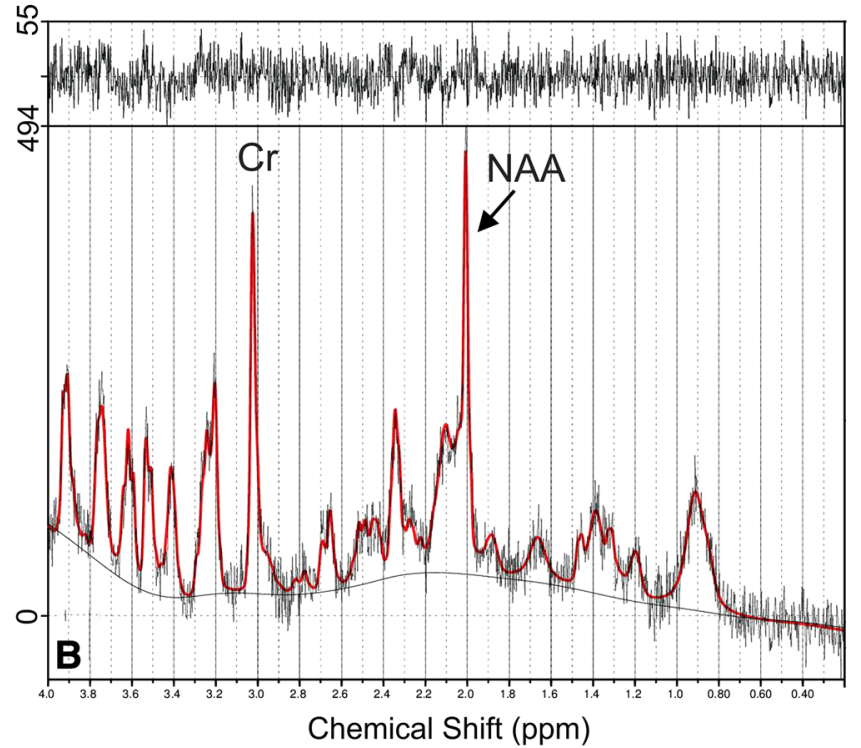

ordinate and abscissa show the relative concentration (signal intensity) and the frequency chemical shift (ppm), respectively. Note different scales of the relative concentration in Figs. A and B

cortex it was $1.8 \times 4 \times 4 \mathrm{~mm}$. Spectrum acquisition took usually $35 \mathrm{~min}$. Reference scan without water suppression (RF power set to 0 ) was also acquired. Quantification of water-scaled metabolite concentration was performed using LCModel version 6.3-1M (Provencher 1999) program (Fig. 2). 
Table 2 Metabolites analysed with MRI spectroscopy

\begin{tabular}{ll}
\hline Metabolite & Symbol \\
\hline Acetone & Acn \\
Acetate & Act \\
L-Alanine & Ala \\
Aspartate & Asp \\
$\beta$-Hydroxybutyrate & bHb \\
Creatine & Cr \\
$\gamma$-Aminobutyric acid & GABA \\
Glucose & Glc \\
Glutamine & Gln \\
Glutamate & Glu \\
Glycerophosphocholine & GPC \\
Glutathione & GSH \\
myo-Inositol & Ins \\
L-Lactate & Lac \\
$N$-Acetylaspartate & NAA \\
$N$-Acetylaspartylglutamate & NAAG \\
Phosphocholine & PCh \\
Phosphocreatine & PCr \\
Taurine & Tau \\
\hline
\end{tabular}

\section{Ex-vivo MRI}

This procedure was performed with a $35 \mathrm{~mm}$ inner diameter quadrature birdcage RF coil (Bruker T9913V3), BFG113/60-S (Resonance Research, Inc. Billerica, MA, USA) gradient coil, and the ParaVision 6.1 software interface. For imaging, a fixed brain was enclosed in a syringe filled with formalin. DTI data were acquired with DtiStandard sequence [field of view (FOV) $18 \times 18 \mathrm{~mm}$, acquisition matrix (MTX) $128 \times 128$, slice thickness (SI) $0.5 \mathrm{~mm}$, number of slices (NS) 46, repetition time (TR) $5000 \mathrm{~ms}$, echo time (TE) $20 \mathrm{~ms}$, number of averages (NEX) 4, 30 diffusion gradient directions, $b$-factor $1000 \mathrm{~s} / \mathrm{mm}^{2}$, time between diffusion gradient pulses $(\Delta) 10 \mathrm{~ms}$, diffusion gradient duration $(\delta)$ $2.5 \mathrm{~ms}$ ]. Morphological T2 weighted images of the rat brain were acquired with RARE sequence [FOV $18 \times 18 \mathrm{~mm}$, MTX $256 \times 256$, SI $0.25 \mathrm{~mm}$, NS 94, TR $3700 \mathrm{~ms}$, TE $12.8 \mathrm{~ms}$, turbo factor 4].

\section{Tractography}

The tractography was obtained using DSI Studio (https:// dsi-studio.labsolver.org). Diffusion MRI dataset was reconstructed with simple diffusion tensor model (DTI), giving high validation of connections (Maier-Hein et al. 2017). The deterministic streamline tracking algorithm was applied to the following regions selected manually in accordance to Waxholm Rat scalable brain atlas (Bakker et al. 2015; Papp et al. 2014; Kjonigsen et al. 2015; Sergejeva et al. 2015): anterior commissure, corpus callosum, fimbria-fornix, hippocampal formation, internal capsule, striatum and pons. The measured fibers were related to each of the specified brain regions and labeled here with respective symbols: (1) fibers go through the region of interest (ROI); (2) fibers do not go through that region (region of avoidance, ROA), (3) fibers enter that region and do not go further (END). Fractional anisotropy (FA) was used as a termination index with a threshold value equal to 0.15 , angular threshold was set to 75 degrees, and the tracking algorithm was stopped after 20,000 seeds. Figure 3 shows examples of the obtained tractograms.

\section{Statistical analyses}

Normality of data and homogeneity of variance were checked with the Shapiro-Wilk and Levene's tests, respectively. Because of normal distribution of the data, concentration levels of the examined metabolites were compared between groups using Student's t tests for repeated measures or independent samples. Relationships between the concentration parameters were assessed by calculation of Pearson's correlation coefficients. The level of statistical significance was set at 0.05. Statistical analyses were performed with Statistica 10 (Statsoft).

\section{Results}

\section{Diet parameters}

Measurements of food consumption per one animal showed that the average daily food intake was $20.0 \mathrm{~g}$ of normal (ND) and $10.5 \mathrm{~g}$ ketogenic diet (KD), providing 61.1 and $87.5 \mathrm{kcal} /$ day, respectively.

It was observed that from the 11th week of experiment that the body weight of animals on KD was significantly higher than that of animals on ND (Gzielo et al. 2019). Despite that difference, very similar correlations were detected between the food intake and the weight of animals in each group (ND, $r=0.903, p<0.000001$; KD, $r=0.912$, $p<0.00001)$.

\section{Blood parameters}

Ketone body blood concentration in animals at the second measurement (the first after the diet introduction) was significantly higher in animals on KD (Fig. 4). However, the average glucose level in all animal groups remained at $97 \mathrm{mM} / \mathrm{L}$, but a significant correlation occurred between the ketone bodies and glucose levels in rats on KD (Fig. 5; $r=-0.503 ; p=0.000001)$. 
Fig. 3 Examples of tractograms. Distribution of fibers belonging to the $3+$ length class ending in the striatum in animals after 4-month-lasting normal (ND, a and $\mathbf{b})$ or ketogenic $(\mathrm{KD}, \mathbf{c}$ and d) diets. Fiber length classes are defined in "Results"
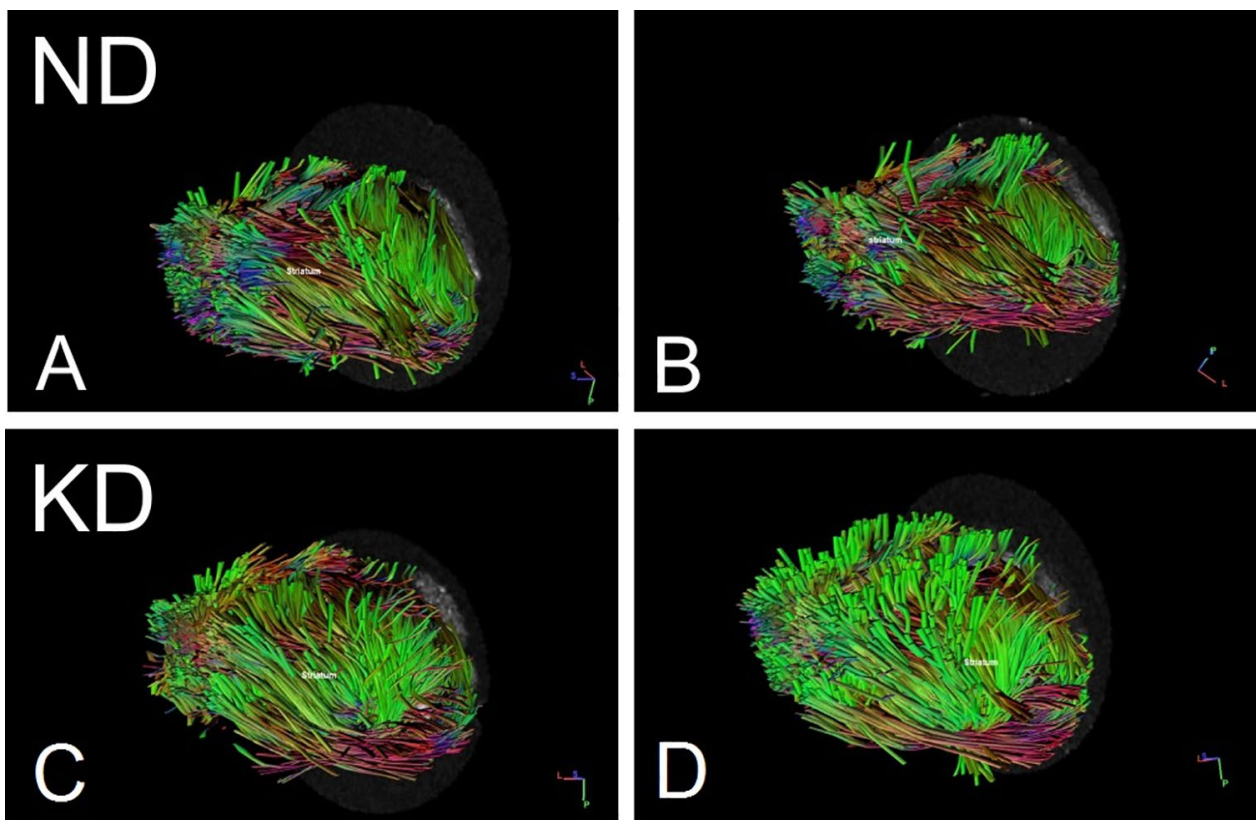

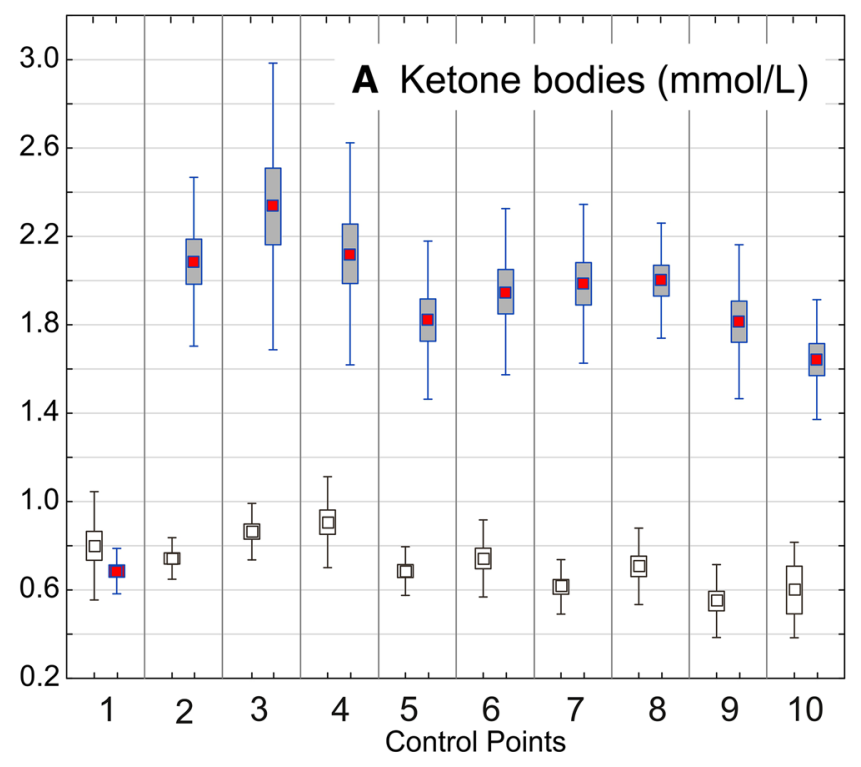

Fig. 4 Blood levels of ketone bodies (a) and of glucose (b) measured at the beginning of the experiment (control point 1 ) then every 2 weeks (control points 2-10). In a, all the differences between KD-treated and control groups are statistically significant at least at $p<0.00001$, with exception of that at the control point 1 representing

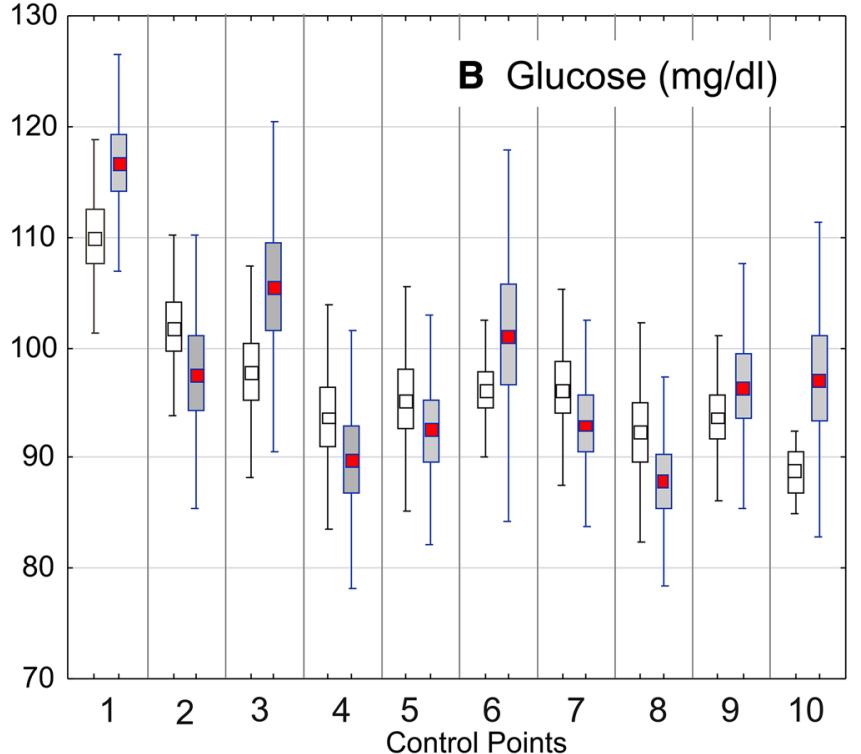

the time when ketogenic diet was introduced (control point 1$)$. The results are presented as means $( \pm$ SEM and SD; Student's $t$ test) for animal groups on 4-month normal (white squares) or ketogenic diets (red squares), respectively
Before the end of the experiment (immediately before perfusion-fixation), the peripheral blood count was performed including HCT, HGB, MCH, MCHC, MCV, PLT, 
Fig. 5 Correlation between blood levels of ketone bodies and glucose in rats on ketogenic diet. Pearson's coefficient of correlation $(r)$ is shown here with the index of statistical significance $(p)$. A solid diagonal line shows a linear fit for the correlation

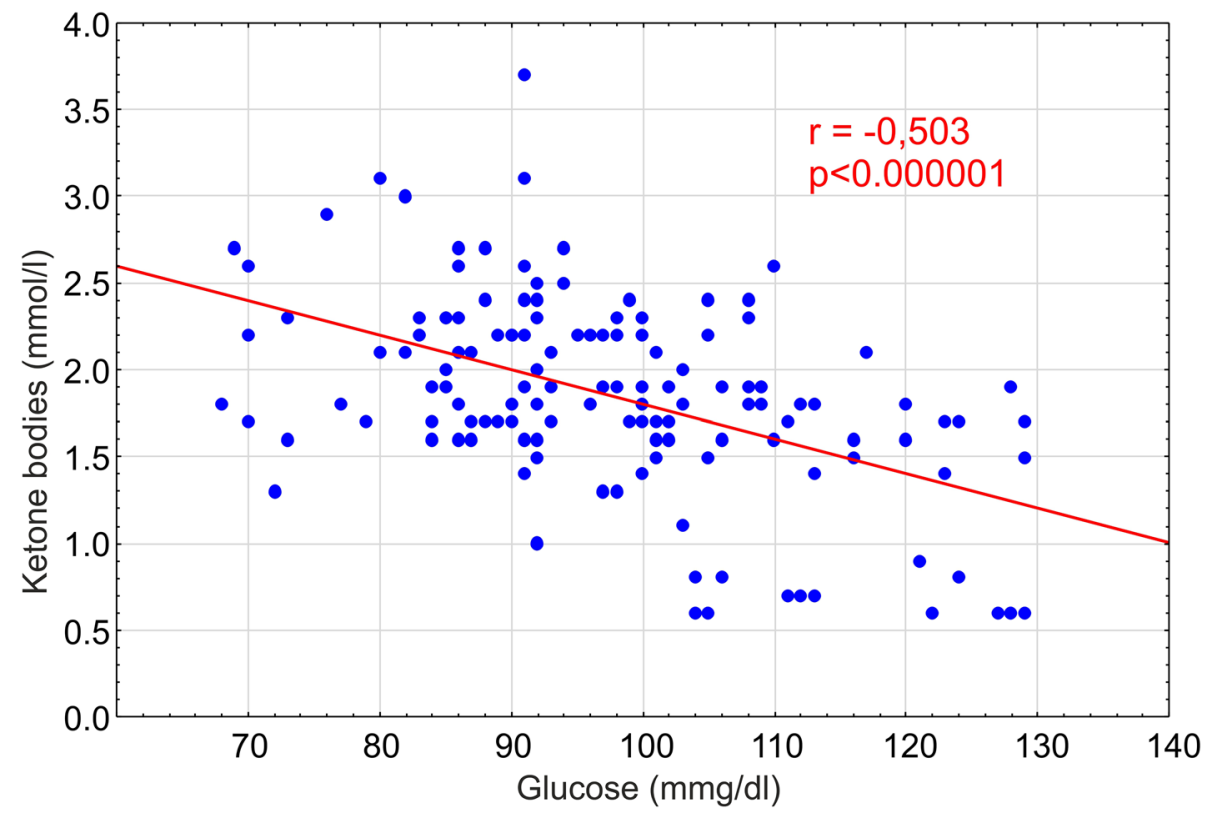

A Neocortex
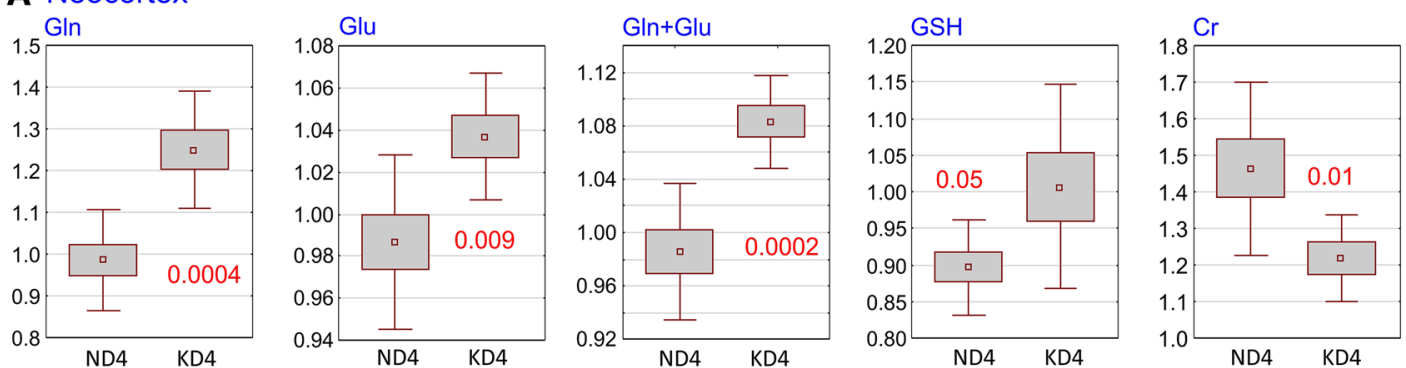

B Hippocampal formation
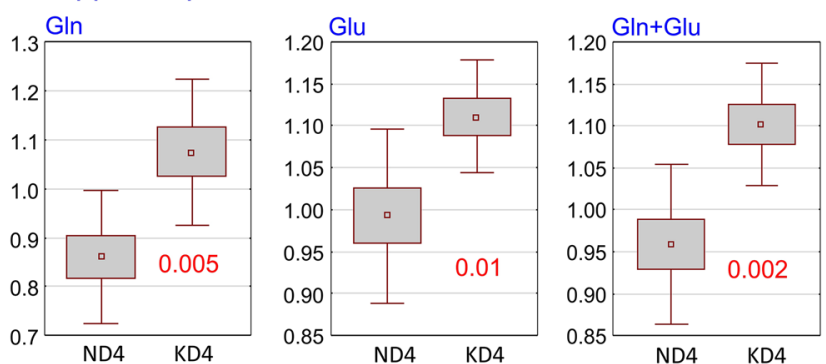

Fig. 6 Changes in the concentration of selected metabolites in the cerebral cortex and hippocampal formation. The results are presented as means ( \pm SEM and SD; Student's $t$ test) together with indexes of

$\mathrm{RBC}, \mathrm{WBC}$ without detection of a significant intergroup difference in the parameters tested. Biochemical blood tests of ALP, LDH, Kre, TG, CPK, UA detected statistically significant increases in ALP (alkaline phosphatase) $(p<0.0034)$ and TG $(p<0.0009)$ in the group on KD. In this group, the bHb level was also significantly increased (Gzielo et al. 2019).
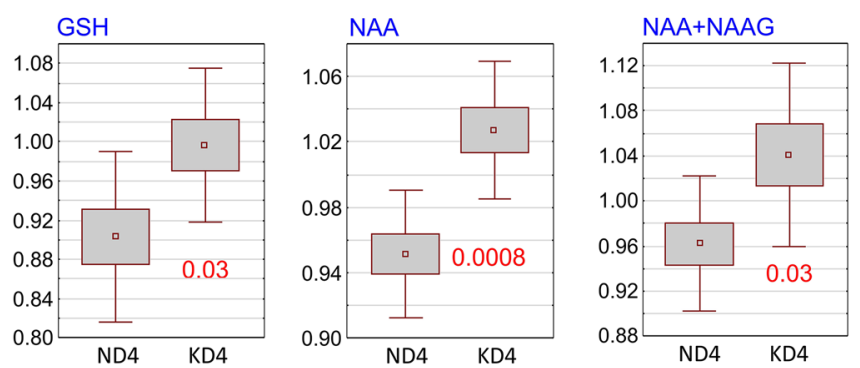

statistical significance (decimal fractions). ND4 and KD4-groups of animals on a 4-month normal or ketogenic diets, respectively. Abbreviations for metabolites are explained in "Materials and methods"

\section{Metabolite concentration: MRI spectroscopy}

After 4 months of KD, significant increases in concentrations of Glu, Gln, Glu + Gln, and GSH were observed in the cerebral cortex with a decrease in $\mathrm{Cr}$ (Fig. 6a). In contrast, the concentrations of GABA, Glc, GPc, Ins, NAA, NAA + NAG, Pch, Pcr, Tau remained stable. The hippocampal formation of KD-treated animals, showed 
significantly increased concentrations of Gln, Glu, Glu + Gln, GSH, NAA and NAA + NAG. No changes in the concentration of GABA, Glc, Gpc, Ins, Pch, Tau, Ala, Lac were observed (Fig. 6b). Both the cerebral cortex and hippocampal formation showed no significant change of the ratio between Glu and GABA levels.

\section{Structural ex vivo MRI}

On the MRI structural scans from brains of animals subjected to 4-month-lasting standard or ketogenic diets, volumes of the brain and of its regions related to the total brain volume were calculated. The measured regions were: the cerebral cortex, cerebral ventricles, hippocampal formation, striatum, midbrain and pons. The only statistically significant difference was that in the pons volume, which was significantly smaller in animals on KD $(p<0.04)$.

\section{Tractography}

Based on ex vivo DTI fractional anisotropy measurements, myelinated fibers were divided into three classes, according to their minimum length, i.e. which were at least (i) $3 \mathrm{~mm}$, (ii) $10 \mathrm{~mm}$ or (iii) $30 \mathrm{~mm}$ long. The classes are termed here as fibers $3+, 10+$ or $30+$, respectively. Myelinated fibers shorter than $3 \mathrm{~mm}$ were excluded from the analyses.

The DTI measurements revealed significant changes in the quantity, total length, total volume, and level of fractional anisotropy (FA) of fibers falling into each of these three classes and related to brain structures presented below (Table 3).

\section{Striatum (Table 2/1-5)}

The greatest changes in the distribution of myelinated nerve fibers occurred in relation to the striatum. Fibers $3+\mathrm{mm}$ ending in the striatum increased in their number $(p<0.005)$ and total volume $(p<0.00006)$. There were also increases

Table 3 Distribution of myelinated fibers

\begin{tabular}{|l|c|c|c|c|c|}
\hline \multicolumn{1}{|c|}{$\begin{array}{c}\text { Fibers related to brain } \\
\text { structures }\end{array}$} & $\begin{array}{c}\text { Fiber } \\
\text { length } \\
\text { class }\end{array}$ & $\begin{array}{c}\text { Fiber } \\
\text { quantity }\end{array}$ & $\begin{array}{c}\text { Total fiber } \\
\text { length }\end{array}$ & $\begin{array}{c}\text { Total fiber } \\
\text { volume }\end{array}$ & $\begin{array}{c}\text { Fractional } \\
\text { anizotropy }\end{array}$ \\
\hline 1. striatum END & $3+$ & $\begin{array}{c}0.25 \\
0.005\end{array}$ & & $\begin{array}{c}0.19 \\
0.00006\end{array}$ & \\
\hline 2. striatum ROI & $3+$ & $\begin{array}{c}0.19 \\
0.02\end{array}$ & & $\begin{array}{c}0.22 \\
0.04\end{array}$ & \\
\hline 3. striatum ROA & $3+$ & $\begin{array}{c}-0.17 \\
0.04\end{array}$ & & & \\
\hline 4. Striatum ROI & $10+$ & $\begin{array}{c}0.27 \\
0.02\end{array}$ & & & 0.27 \\
\hline 5. striatum ROA & $10+$ & $\begin{array}{c}-0.36 \\
0.02\end{array}$ & & -0.23 & -0.36 \\
& $10+$ & & 0.23 & & 0.04 \\
6. hippocampal form. ROI & 10.02 & \\
\hline 7. hippocampal form. ROI & $30+$ & $\begin{array}{c}0.30 \\
0.05\end{array}$ & & & 0.16 \\
\hline 8. fimbria-fornix END & $30+$ & $\begin{array}{c}0.89 \\
0.03\end{array}$ & & & 0.03 \\
\hline 9. internal capsule END & $3+$ & -0.41 & & -0.33 & \\
\hline 10. pons END & $10+$ & & 0.19 & & \\
\hline
\end{tabular}

Tractography analysis of myelinated fibers distribution was related to particular brain regions including the striatum, hippocampal formation, fimbria-fornix, internal capsule, and pons. Depending on their relations to brain regions, the fiber was defined as: ROI-fibers passing through a given region; ROA - fibers not passing through that region (region of avoidance); END—-fibers entering but not leaving that region (end region). Fibers related to particular brain regions were characterized using four parameters: (1) total quantity, (2) total length, (3) total volume, and (4) fractional anisotropy. Symbols 3+, 10+and 30+ indicate length classes of fibers defined by their minimum length, i.e. which were at least (i) $3 \mathrm{~mm}$, (ii) $10 \mathrm{~mm}$ or (iii) $30 \mathrm{~mm}$ long, respectively. Decimal coefficients (in black) show relative changes in values of particular parameters obtained by dividing differences between means from KD-treated (Mkd) and control groups (Mcon) by the mean from the control group (Mcon), i.e. using the following formula: (Mkd-MNcon)/Mcon. Increases and decreases are indicated by up- and down-oriented arrows (in green and red, respectively) with decimal indexes of statistical significance (Student's $t$ test for independent samples) 
in the number $(p<0.02)$ and volume $(p<0.04)$ of fibers $3+$ mm passing through the striatum without ending in it. Respectively, the number of fibers $3+\mathrm{mm}$ that bypassed the striatum became significantly lower $(p<0.04)$. The number of fibers $10+\mathrm{mm}$ that passed through the striatum increased $(p<0.02)$, while the number $(p<0.02)$ and volume $(p<0.04)$ of those that bypassed the striatum $(p<0.02)$ decreased. This increase and decreases were correspondingly accompanied by an higher $(p<0.02)$ and a lower $(p<0.02)$ FA values.

\section{Hippocampal formation of fimbria-fornix (Table 2/6-8)}

The total length of fibers $3+\mathrm{mm}$ passing through this region increased $(p<0.04)$. Also numbers of fibers $30+\mathrm{mm}$ passing through the hippocampal formation increased $(p<0.05)$ with an elevation in their FA $(p<0.03)$. There was also an increase in the number of fibers $30+\mathrm{mm}$ ending in fimbria-fornix $(p<0.03)$.

\section{Internal capsule (Table 2/9)}

Significant decreases in the number $(p<0.03)$ and volume $(p<0.04)$ of fibers $3+\mathrm{mm}$ terminating in this region were detected.

\section{Pons (Table 2/10)}

Among all analyzed, only an increase in the total length of fibers $10+$ was found as statistically significant $(p<0.03)$.

\section{Discussion}

To our best knowledge, this is the first study on effects of long-term feeding of $\mathrm{KD}$ in young adult rats, which were not subjected to any previous experimental procedure simulating a neurodegenerative disease. The study has shown that the 4-month-lasting ketogenic diet changed the metabolism and structure of the brain in normal, healthy animals. First, the changes were observed in the blood. As in other studies, after 1 week of KD consumption, the level of ketone bodies significantly increased in peripheral blood, which was the natural evidence of the treatment application. Also, in blood collected from the heart immediately before perfusion, the level of bHb was significantly higher (Gzieło et al. 2019). The glucose level remained normal, which was in agreement with Zhang et al. (2018a, b) who explained this fact as the result of adaptation to a long stay on a carbohydratefree diet. Importantly, the morphotic blood elements were not affected, which suggests that these parameters were not modified when this diet was used in individuals suffering, for example, from epilepsy.
Since ketone bodies formed during the ketogenic diet can penetrate BBB, different parts of the central nervous system can also be affected but at different degrees. Our research was focused on changes in concentration of the most important brain metabolites occurring in the neocortex and hippocampal formation after 4 month-lasting KD. Level of the metabolites was measured with magnetic resonance spectroscopy frequently used not only for experimental approach but also in clinical diagnostic tests. Most of the metabolite levels did not change, which suggests that ketone bodies are rather not involved in all metabolic pathways within the nervous tissue.

The changes that we observed in both the cortex and hippocampal formation affected, among others, the levels of Glu and Gln which were significantly higher after 4-monthlasting KD than after normal diet. Glu is the most common excitatory neurotransmitter in the nervous system. Its occurrence and action are closely related to Gln via the Glu-Gln cycle. After being released from synapses, Glu is taken up by adjoining astrocytes, transformed into Gln, and then transported back to the neuron (Danbolt et al. 2016). That is why it was not surprising in our research that the increase in Glu after KD was accompanied by an increase in Gln level. The energetic cost of Glu uptake is very high-at 1.5 ATP molecules per one Glu molecule transported. Therefore, the large involvement of astrocytes in this process protects neurons from metabolic overload (Danbolt et al. 2016). For this uptake, KD provides more energy than a normal diet because metabolized fat delivers more energy than glucose (Włodarek 2019). Even though Glu is a precursor of GABA, in our study, the level of GABA did not undergo a corresponding KD-induced change. Also, no significant change was detected in the ratio of Glu to GABA concentration both in relation to the stage before KD introduction in the same animal group and to the control group fed with normal diet. Since GABA is the most important inhibitory neurotransmitter, increases in its level are postulated to determine epileptic seizure inhibition in response to KD (Yudkoff et al. 2008; Greene et al. 2003; Maalouf et al. 2009). In addition, Glu can act via ionotropic IGluRs receptors and enhance GABA secretion by inhibitory neurons (Mahmoud et al. 2019). However, KD does not always lead to increases in GABA content. As in our own study, KD-induced elevation of GABA did not occurr in the mouse forebrain and cerebellum (Yudkoff et al. 2001), mouse whole brain (Yudkoff et al. 2005), mouse neocortex (Melo et al. 2006) or in the whole rat brain (Hartman et al. 2007). Supposedly, the lack of changes in GABA concentration in our study resulted from the fact that we were focused on KD effects in normal animals but not in those under pathological conditions which can influence molecular interactions differently. This problem needs further investigations. 
Another postulated mechanism of KD action is a decrease in oxygen free radical production. Such an antioxidant effect may be caused by increased levels of glutathione, which was also observed here. This is most likely associated with an increase in glutathione peroxidase activity. It is suggested that higher activity of this enzyme, induced by $\mathrm{KD}$, may be protective against neurodegenerative changes (Ziegler et al. 2003). In addition, it is believed that most GSH-dependent detoxification processes occur in astrocytes (FernandezFernandez et al. 2012), which confirms the involvement of these cells in the protective KD effects.

Our analyzes also showed a decrease in creatine concentration in the cerebral cortex. In our previous research using synchrotron radiation, an increase in the number of creatine deposits was detected in the hippocampal formation following 30-day-lasting KD (Skoczen et al. 2017). This discrepancy is probably due to different creatine content in particular brain structures. Creatine in the brain and its phosphorylated form acts as an energy reservoir necessary, among others, to maintain membrane potential (Kurosawa and Hamaoka 2017). Probably, during 4 months on KD, ketone bodies became the source of this energy, which is why in the cortex a decrease in the creatine content was observed while in the hippocampal formation it remained stable.

The above-mentioned changes in levels of metabolites associated with glial cells were accompanied by an increase in NAA found in the hippocampal formation. $N$-Acetylaspartate is one of the most common molecules in the brain. Its unique properties determine its extremely high concentration in the brain and its strong signal recorded with magnetic resonance spectroscopy (Setkowicz et al. 2015). Thus, it is represented by the largest peak in the spectrum of healthy brain tissue (Moffett et al. 2007) and its decrease is characteristic of many pathological conditions including, among others, different brain damages, ischemia, cancer, multiple sclerosis, or Alzheimer disease, (Danielsen and Ross 1999).

Despite the prevalence of NAA in the brain, its role remains not fully understood. It is thought to act as an osmolyte compensating anion deficiencies in neurons. It is considered as a precursor to NAAG dipeptide and the source of acetate necessary for the synthesis of myelin lipids. Supposedly, NAA supports the metabolism of neuronal mitochondria (Moffett et al. 2007). It is located in neurons. including their processes, at levels depending on specificity of a given neuronal population (Moffett et al. 2007). Besides that, strong interactions between glial cells and neurons mediated by NAA were detected. Baslow (2000) described this signaling pathway considering the fact that both NAA and NAAG are synthesized in neurons while the related catabolic enzymes are found in oligodendrocytes and astrocytes.
Therefore, NAA released from neurons may be a signal for oligodendrocytes and NAAG for astrocytes (Moffett et al. 2007). Then, after completing the appropriate catabolic reactions in target cells, the substrates can be reutilized by neurons for NAA and NAAG resynthesis. It can be concluded that the elevation of NAA and NAAG contents following $\mathrm{KD}$ is a natural functional consequence of presence of NAA as the source of acetoacetate for the production of myelin. The number of mitochondria and levels of their metabolism increase (Hartman et al. 2007), so it seems to lead to higher concentration of NAA, which is involved in energy processes in mitochondria. Thus, the supply of substrates necessary for the myelination process increases, affecting particular brain regions differently.

Following the high fat diet conditions in our investigation, the striatum, as the biggest brain region of interest, showed the most spectacular signs of increases in myelinated fibers. These increases were accompanied by declines in parameters for fibers bypassing the striatum and other ending in the internal capsule. It can be assumed that the two fiber components might, at least partially, overlap each other and form a part of connections with the neocortex. The striatum controls motor functions through brainstem structures and pathways passing through the pons. Thus, the relatively small increases in the pons volume and in the length of $10+$ fibers terminating in it could have been associated with the increases found in the striatum. The hippocampal formation and fimbria-fornix, belonging to the same functional subsystem, show consistent increases in $3+$ and $30+$ fibers which may have functional effects.

All these results indicate that KD could evoke significant changes in intracerebral connections but, because of their preliminary and general character, particular fiber components cannot be recognized.

The effect of ketogenic diet on the intracerebral connectivity has not yet been studied. Our tractography measurements revealed the strongest significant increases related to the striatum, the area responsible for animal movement. Available data on the effect of ketogenic diet on locomotor activity is ambiguous (Murphy et al. 2005; Murphy and Burnham 2006; Thio et al. 2010), and those on the motor system in the normal brain are very rare. So far, KD effects have been reported in diseases with substantial motor dysfunctions and in corresponding rodent models of Alzheimer's and Parkinson's diseases, amyotrophic lateral sclerosis, or spinal cord injury (Veyrat-Durebex et al. 2018). Little is known about the molecular mechanisms underlying observed improvements, especially when only a selective local impact on the striatum would be considered, including associated increases in the fiber quantity. The subject of our research was the impact of KD on the normal brain, and this means the absence of a pathological condition that can significantly modify the consequences of KD. 
In KD-treated rats, an elevated expression of glutamate decarboxylase was detected in the striatum (Cheng et al. (2004). This could be indirect evidence of functional changes in this brain region since this enzyme is involved in GABA synthesis. In the present study, we found quantitative increases in fibers related not only with the striatum but also with the hippocampal formation and fornix. Selective KD effects on these regions, but not on the cerebral cortex, were reported by Zarnowski et al. (2012) but concerning increased levels of kynurenic acid (KA). Similarly to the present study, this regional effect was detected in normal animals without any extra pathological influences. However, Dabrowski et al. (2015) reported that, in the spinal cord, myelin was negatively affected by elevated KA concentration, so it could rather not promote increases in fiber quantities like those in our study. The very diversified results obtained for different regions of the central nervous system might also indicate possible differences between local responses to KD action (Cheng et al., 2004) or even between responses within the same region (Balietti et al. 2008). This might also depend on changes in a local functional status or the type of neuronal subsystems within a given structure. Therefore, these results need more detailed examinations.

\section{Conclusions}

The present study showed that KD applied to normal animals had a little effect on general brain anatomy, detected only as a volumetric increase of the pons. However, significant changes occurred in the pattern of intracerebral connections. They were most strongly related to the striatum and appeared to point to changes in the role of this region in the entire neural network of the brain. At the same time, as the result or cause of these changes, there were increases in the concentrations of metabolites being of critical functional importance for the nervous system such as NAA, glutamate or glutathione. Since the most significant changes were related to metabolites associated with glial cells, especially astrocytes, it can be assumed that these cells are the main target of KD and can also underlie its neuroprotective effects. Confirmation requires further research.

Author contributions Conception and design (ZS). Material preparation, data collection, and analysis were performed by $(\mathrm{ZS}, \mathrm{KJ}, \mathrm{KG}$, $\mathrm{KJ}$, and $\mathrm{WW}$ ). The figures were made by KJ. The first draft of the manuscript was written by ZS and all authors commented on previous versions of the manuscript.

Funding This study was funded by National Science Centre, Poland, Grant No. 2015/17/B/NZ7/02953. The open-access publication of this article was funded by the Priority Research Area BioS under the program "Excellence Initiative - Research University" at the Jagiellonian University in Krakow.

\section{Compliance with ethical standards}

Conflict of interest The authors have no conflict of interest to declare.

Human and animal participants right statement This article does not contain any studies involving human participants that were performed by any of the authors.

Open Access This article is licensed under a Creative Commons Attribution 4.0 International License, which permits use, sharing, adaptation, distribution and reproduction in any medium or format, as long as you give appropriate credit to the original author(s) and the source, provide a link to the Creative Commons licence, and indicate if changes were made. The images or other third party material in this article are included in the article's Creative Commons licence, unless indicated otherwise in a credit line to the material. If material is not included in the article's Creative Commons licence and your intended use is not permitted by statutory regulation or exceeds the permitted use, you will need to obtain permission directly from the copyright holder. To view a copy of this licence, visit http://creativecommons.org/licenses/by/4.0/.

\section{References}

Bailey EE, Pfeifer HH, Thiele EA (2005) The use of diet in the treatment of epilepsy. Epilepsy Behav 6:4-8. https://doi.org/10.1016/j. yebeh.2004.10.006

Bakker R, Tiesinga P, Kötter R (2015) The Scalable Brain Atlas: instant web-based access to public brain atlases and related content. Neuroinformatics 13:53-366. https://doi.org/10.1007/ s12021-014-9258-X

Balietti M, Giorgetti B, Fattoretti P, Grossi Y, Di Stefano G, Casoli T, Platano D, Solazzi M, Orlando F, Aicardi G, BertoniFreddari C (2008) Ketogenic diets cause opposing changes in synaptic morphology inCA1 hippocampus and dentate gyrus of late-adult rats. Rejuvenation Res 11:631-640. https://doi. org/10.1089/rej.2007.06

Baslow MH (2000) Functions of $N$-acetyl-L-aspartate and $N$-acetylL-aspartylglutamate in the vertebrate brain: role in glial cell-specific signaling. J Neurochem 75:453-459. https://doi.org/10.104 6/j.1471-4159.2000.0750453.x

Cheng CM, Hicks K, Wang J, Eagles DA, Bondy CA (2004) Caloric restriction augments brain glutamic acid decarboxylase-65 and -67 expression. J Neurosci Res 15:270-276. https://doi.org/10.1002/ jnr.20144

Dabrowski W, Kwiecien JM, Rola R, Klapec M, Stanisz GJ, Kotlinska-Hasiec E, Oakden W, Janik R, Coote M, Frey BN, Turski WA (2015) Prolonged subdural infusion of kynurenic acid is associated with dose-dependent myelin damage in the rat spinal cord. PLoS ONE 10(11):e0142598. https://doi.org/10.1371/journ al.pone. 0142598

Dahlin M, Elfving A, Ungerstedt U, Amark P (2005) The ketogenic diet influences the levels of excitatory and inhibitory amino acids in the CSF in children with refractory epilepsy. Epilepsy Res 64:115-125. https://doi.org/10.1016/j.eplepsyres.2005.03.008

Danbolt NC, Furness DN, Zhou Y (2016) Neuronal vs glial glutamate uptake: resolving the conundrum. Neurochem Int 98:29-45. https ://doi.org/10.1016/j.neuint.2016.05.009

Danielsen ER, Ross B (1999) Magnetic resonance spectroscopy diagnosis of neurological diseases. CRC Press, Boca Raton (ISBN 9780824702380)

Fernandez-Fernandez S, Almeida A, Bolanos JP (2012) Antioxidant and bioenergetic coupling between neurons and astrocytes. Biochem J 442:3-12. https://doi.org/10.1042/BJ20111943 
Gama IR, Trindade-Filho EM, Oliveira SL, Bueno NB, Melo IT, Cabral-Junior CR, Barros EM, Galvão JA, Pereira WS, Ferreira RC, Domingos BR, da Rocha AT (2015) Effects of ketogenic diets on the occurrence of pilocarpine-induced status epilepticus of rats. Metab Brain Dis 30:93-98. https://doi.org/10.1007/s1101 1-014-9586-4

Greene AE, Todorova MT, Seyfried TN (2003) Perspectives on the metabolic management of epilepsy through dietary reduction of glucose and elevation of ketone bodies. J Neurochem 86:529-537. https://doi.org/10.1046/j.1471-4159.2003.01862.x

Guzman M, Blazquez C (2001) Is there an astrocyte-neuron ketone body shuttle? Trends Endocrinol Metab 12:169-173. https://doi. org/10.1016/s1043-2760(00)00370-2

Gzielo K, Kielbinski M, Ploszaj J, Janeczko K, Gazdzinski SP, Setkowicz Z (2017) Long-term consumption of high-fat diet in rats: effects on microglial and astrocytic morphology and neuronal nitric oxide synthase expression. Cell Mol Neurobiol 37:783-789. https://doi.org/10.1007/s10571-016-0417-5

Gzielo K, Soltys Z, Rajfur Z, Setkowicz ZK (2019) The impact of the ketogenic diet on glial cells morphology. A quantitative morphological analysis. Neuroscience 413:239-251. https://doi. org/10.1016/j.neuroscience.2019.06.009

Hartman AL, Gasior M, Vining EP, Rogawski MA (2007) The neuropharmacology of the ketogenic diet. Pediatr Neurol 36:281-292. https://doi.org/10.1016/j.pediatrneurol.2007.02.008

Huang J, Li YQ, Wu CH, Zhang YL, Zhao ST, Chen YJ, Deng YH, Xuan A, Sun XD (2019) The effect of ketogenic diet on behaviors and synaptic functions of naive mice. Brain Behav 9:e01246. https ://doi.org/10.1002/brb3.1246

Jarrett SG, Milder JB, Liang LP, Patel M (2008) The ketogenic diet increases mitochondrial glutathione levels. J Neurochem 106:1044-1051. https://doi.org/10.1111/j.1471-4159.2008.05460 .x

Kjonigsen LJ, Lillehaug S, Bjaalie JG, Witter MP, Leergaard TB (2015) Waxholm Space atlas of the rat brain hippocampal region: three-dimensional delineations based on magnetic resonance and diffusion tensor imaging. NeuroImage 108:441-449. https://doi. org/10.1016/j.neuroimage.2014.12.080

Koppel SJ, Swerdlow RH (2017) Neuroketotherapeutics: a modern review of a century-old therapy. Neurochem Int 117:114-125. https://doi.org/10.1016/j.neuint.2017.05.019

Kurosawa Y, Hamaoka T (2017) Creatine in the brain. J Phys Fit Sports Med 6:215-217. https://doi.org/10.7600/jpfsm.6.215

Maalouf M, Rho JM, Mattson MP (2009) The neuroprotective properties of calorie restriction, the ketogenic diet, and ketone bodies. Brain Res Rev 59:293-315. https://doi.org/10.1016/j.neuroscien ce.2006.11.065

Mahmoud S, Gharagozloo M, Simard C, Gris D (2019) Astrocytes maintain glutamate homeostasis in the CNS by controlling the balance between glutamate uptake and release. Cells 20:2-27. https://doi.org/10.3390/cells8020184

Maier-Hein KH, Neher PF, Houde JC, Côté MA, Garyfallidis E, Zhong J, Chamberland M, Yeh FC, Lin YC, Ji Q, Reddick WE, Glass JO, Chen DQ, Feng Y, Gao C, Wu Y, Ma J, He R, Li Q, Westin CF, Deslauriers-Gauthier S, González JOO, Paquette M, StJean S, Girard G, Rheault F, Sidhu J, Tax CMW, Guo F, Mesri HY, Dávid S, Froeling M, Heemskerk AM, Leemans A, Boré A, Pinsard B, Bedetti C, Desrosiers M, Brambati S, Doyon J, Sarica A, Vasta R, Cerasa A, Quattrone A, Yeatman J, Khan AR, Hodges W, Alexander S, Romascano D, Barakovic M, Auría A, Esteban O, Lemkaddem A, Thiran JP, Cetingul HE, Odry BL, Mailhe B, Nadar MS, Pizzagalli F, Prasad G, Villalon-Reina JE, Galvis J, Thompson PM, Requejo FS, Laguna PL, Lacerda LM, Barrett R, Dell'Acqua F, Catani M, Petit L, Caruyer E, Daducci A, Dyrby TB, Holland-Letz T, Hilgetag CC, Stieltjes B, Descoteaux M (2017) The challenge of mapping the human connectome based on diffusion tractography. Nat Commun 8 1349. https://doi. org/10.1038/s41467-017-01285-x

Melo TM, Nehlig A, Sonnewald U (2006) Neuronal-glial interactions in rats fed a ketogenic diet. Neurochem Int 48:498-507. https:// doi.org/10.1016/j.neuint.2005.12.037

Moffett JR, Ross B, Arun P, Madhavarao ChN, Namboodiri MAA (2007) $N$-Acetylaspartate in the CNS: from neurodiagnostics to neurobiology. Prog Neurobiol 81:89-131. https://doi. org/10.1016/j.pneurobio.2006.12.003

Murphy P, Burnham WM (2006) The ketogenic diet causes a reversible decrease in activity level in Long-Evans rats. Exp Neurol 201:84-89. https://doi.org/10.1016/j.expneurol.2006.03.024

Murphy P, Likhodii SS, Hatamian M, McIntyre Burnham W (2005) Effect of the ketogenic diet on the activity level of Wistar rats. Pediatr Res 57:353-357. https://doi.org/10.1203/01.PDR.00001 50804.18038.79

Noh HS, Kang SS, Kim DW, Kim YH, Park CH, Han JY, Cho GJ, Choi WS (2005) Ketogenic diet increases calbindin-D28k in the hippocampi of male ICR mice with kainic acid seizures. Epilepsy Res 65:153-159. https://doi.org/10.1016/j.eplepsyres.2005.05.008

Papp EA, Leergaard TB, Calabrese E, Johnson GA, Bjaalie J (2014) Waxholm Space atlas of the Sprague Dawley rat brain. NeuroImage 97:374-386. https://doi.org/10.1016/j.neuroimage .2014.04.001

Provencher SW (1999) Estimation of metabolite concentrations from localized in vivo proton NMR spectra. Magn Reson Med 30:672679. https://doi.org/10.1002/mrm.1910300604

Rardin MJ, Newman JC, Held JM, Cusack MP, Sorensen DJ, Li B, Schilling B, Mooney SD, Kahn CR, Verdin E, Gibson BW (2013) Label-free quantitative proteomics of the lysine acetylome in mitochondria identifies substrates of SIRT3 in metabolic pathways. Proc Natl Acad Sci USA 110:6601-6606. https://doi. org/10.1073/pnas.1302961110

Roya M, Nugenta S, Tremblay-Merciera J, Tremblayc S, CourchesneLoyera A, Beaudoinc JF, Tremblayc L, Descoteauxe M, Lecomtec R, Cunnanea SC (2012) The ketogenic diet increases brain glucose and ketone uptake in aged rats: a dual tracer PET and volumetric MRI study. Brain Res 1488:14-23. https://doi.org/10.1016/j.brain res.2012.10.008

Sergejeva M, Papp EA, Bakker R, Gaudnek MA, Okamura-Oho Y, Boline J, Bjaalie JG, Hess A (2015) Anatomical landmarks for registration of experimental image data to volumetric rodent brain atlasing templates. J Neurosci Methods 240:161-169. https://doi. org/10.1016/j.jneumeth.2014.11.005

Setkowicz Z, Ciarach M (2007) Neuroprotectants FK-506 and cyclosporin A ameliorate the course of pilocarpine-induced seizures. Epilepsy Res 73:151-155. https://doi.org/10.1016/j.eplepsyres .2006 .09 .001

Setkowicz Z, Gaździńska A, Osoba JJ, Karwowska K, Majka P, Orzeł J, Kossowski B, Bogorodzki P, Janeczko K, Wyleżoł M, Gazdzinski SP (2015) Does long-term high fat diet always lead to smaller hippocampi volumes, metabolite concentrations, and worse learning and memory? A magnetic resonance and behavioral study in Wistar rats. PLoS ONE 8(10):e0139987. https://doi.org/10.1371/ journal.pone.0139987

Skoczen A, Setkowicz Z, Janeczko K, Sandt C, Borondics F, Chwiej J (2017) The influence of high fat diets with different ketogenic ratios on the hippocampal accumulation of creatine FTIR microspectroscopy study. Spectrochim Acta A Mol Biomol Spectrosc 5:13-22. https://doi.org/10.1016/j.saa.2017.04.085

Stafstrom CE, Rho JM (2012) The ketogenic diet as a treatment paradigm for diverse neurological disorders. Front Pharmacol 9:3-59. https://doi.org/10.3389/fphar.2012.00059

Thio LL, Rensing N, Maloney S, Wozniak DF, Xiong C, Yamada KA (2010) A ketogenic diet does not impair rat behavior or long-term 
potentiation. Epilepsia 51:1619-1623. https://doi.org/10.111 1/j.1528-1167.2009.02515.x

Vannucci RC, Vannucci SJ (2000) Glucose metabolism in the developing brain. Semin Perinatol 24:107-115. https://doi.org/10.1074/ jbc.M000655200

Veyrat-Durebex C, Reynier P, Procaccio V, Hergesheimer R, Corcia P, Andres CR, Blasco H (2018) How can a ketogenic diet improve motor function? Front Mol Neurosci 11:15. https://doi. org/10.3389/fnmol.2018.00015

Vijay N, Morris ME (2014) Role of monocarboxylate transporters in drug delivery to the brain. Curr Pharm Des 20:1487-1498. https ://doi.org/10.2174/13816128113199990462

Włodarek D (2019) Role of ketogenic diets in neurodegenerative diseases (Alzheimer's disease and Parkinson's disease). Nutrients. 15:1-11. https://doi.org/10.3390/nu11010169

Yudkoff M, Daikhin Y, Nissim I, Lazarow A, Nissim I (2001) Brain amino acid metabolism and ketosis. J Neurosci Res 66:272-281. https://doi.org/10.1002/jnr.1221

Yudkoff M, Daikhin Y, Nissim I, Horyn O, Lazarow A, Luhovyy B, Wehrli S, Nissim I (2005) Response of brain amino acid metabolism to ketosis. Neurochem Int 47:119-128. https://doi. org/10.1016/j.neuint.2005.04.014

Yudkoff M, Daikhin Y, Horyn O, Nissim I, Nissim I (2008) Ketosis and brain handling of glutamate, glutamine, and GABA. Epilepsia 49:73-75. https://doi.org/10.1111/j.1528-1167.2008.01841.x
Zarnowski T, Choragiewicz T, Tulidowicz-Bielak M, Thaler S, Rejdak R, Zarnowska I, Turski WA, Gasior M (2012) Ketogenic diet increases concentrations of kynurenic acid in discrete brain structures of young and adult rats. J Neural Transm 119:679-684. https ://doi.org/10.1007/s00702-011-0750-2

Zhang F, Wu H, Jin Y, Zhang X (2018a) Proton magnetic resonance spectroscopy (H1-MRS) study of the ketogenic diet on repetitive mild traumatic brain injury in adolescent rats and its effect on neurodegeneration. World Neurosurg 120:1193-1202. https://doi. org/10.1016/j.wneu.2018.09.037

Zhang Y, Xu K, Kerwin T, LaManna JC, Puchowicz M (2018b) Impact of aging on metabolic changes in the ketotic rat brain: glucose, oxidative and 4-HNE metabolism. Adv Exp Med Biol 1072:2125. https://doi.org/10.1007/978-3-319-91287-5_4

Ziegler DR, Ribeiro LC, Hagenn M, Siqueira IR, Araújo E, Torres IL, Gottfried C, Netto CA, Gonçalves CA (2003) Ketogenic diet increases glutathione peroxidase activity in rat hippocampus. Neurochem Res 28:1793-1797. https://doi.org/10.1023/a:10261 07405399

Publisher's Note Springer Nature remains neutral with regard to jurisdictional claims in published maps and institutional affiliations. 